Viçosa, MG, DEA/UFV - http://www.seer.ufv.br

\title{
AGUA RESIDUAL DE SUINOCULTURA EN ATRIBUTOS QUÍMICOS DEL SUELO Y TENORES FOLIARES DE SOJA Y MAÍZ
}

\author{
Alfredo Alves Neto ${ }^{1}$, Maria do Carmo $^{2}$, Leandro Rampim ${ }^{3}$, Jéssica Caroline Coppo ${ }^{4}$ \& Luiz Antonio de Mendonça Costa ${ }^{5}$ \\ ${ }^{1}$ Doutorando em agronomía UNIOESTE/ Marechal Cândido Rondon-PR, Alfredo.alves.neto@gmail.com \\ ${ }^{2}$ Doutora, Professora adjunta da UNIOESTE/ Marechal Cândido Rondon-PR, mariac.lana@hotmail.com \\ ${ }^{3}$ Doutor,Professor adjunto da UNICENTRO/Guarapuava-PR, rampimleandro@hotmail.com \\ ${ }^{4}$ Doutoranda de agronomía UEM/Maringá-PR,coppojessica0@gmail.com \\ ${ }^{5}$ Engenheiro Agricola, Pesquisador CNP/Cascavél-PR, Antonio.mendonça@gmail.com
}

\section{Palabras-clave:}

Fósforo

Nitrógeno

Nutrientes foliares

Eutrofización

Reciclaje de nutrientes

\section{RESUMEN}

El uso de abonos orgánicos a través del agua residual de suinocultura (ARS) puede afectar positivamente los atributos químicos del suelo, debiendo ser monitoreado, debido a que un exceso puede constituir un alto contaminante ambiental. El objetivo de este trabajo fue evaluar las alteraciones de atributos químicos del suelo y tenores foliares de los cultivos de soja y maíz segunda zafra en función de aplicaciones de dosis de ARS. El experimento fue conducido en un Rhodic Kandiudox, bajo sistema de siembra directa, en el Centro de Investigación de la Cooperativa Agroindustrial Consolata. Fue utilizado un diseño experimental de bloques al azar con parcelas subdivididas, siendo colocadas en las parcelas principales dosis de 0,35 , 70,105 e $140 \mathrm{~m}^{3} \mathrm{ha}^{-1}$ año ${ }^{-1}$ de ARS, e en las subparcelas, dos niveles de fertilización mineral (ausencia y presencia), para la soja fueron aplicados $300 \mathrm{~kg} \mathrm{ha}^{-1}$ de la formulación 04-24-16 en el momento de la siembra y para el maíz segunda zafra $300 \mathrm{~kg} \mathrm{ha}^{-1}$ de la formulación 10-15-10 durante el periodo comprendido de setiembre de 2013 a agosto de 2014. Posteriormente a la cosecha de maíz, fueron colectadas muestras de suelo en las camadas de 0-0,10 m e 0,10-0,20 $\mathrm{m}$, determinándose carbono orgánico, $\mathrm{P}, \mathrm{K}, \mathrm{Cu}$ y $\mathrm{Zn}$, además de la determinación de tenores foliares de N, P, K, Cu y Zn en los cultivos de soja y maíz de segunda zafra. La aplicación de ARS aumentó los tenores de $\mathrm{P}$ en las camadas 0-0,10 m e 0,10-0,20 m y en los tenores foliares de soja, demostrando que nutrientes contenidos en el ARS pueden ser aprovechados por los cultivos. Las dosis de 105 e $140 \mathrm{~m}^{3}$ ha $^{-1}$ año $^{-1}$ deben ser evitadas debido a la alta concentración de $\mathrm{N}$ y aumento excesivo de tenores de $\mathrm{P}$ en el suelo, que pueden constituir un riesgo ambiental.

\section{Palavras chave:}

Fósforo

Nitrogênio

Nutrientes foliares

Eutrofização

Ciclagem de nutrientes

\section{ÁGUA RESIDUÁRIA DE SUINOCULTURA NOS ATRIBUTOS QUÍMICOS DO SOLO E NOS TEORES FOLIARES DE SOJA E MILHO SEGUNDA SAFRA \\ RESUMO}

O uso de adubação orgânica via água residuária de suinocultura (ARS) pode afetar os atributos químicos do solo, devendo ser monitorado, visto que em excesso pode ser contaminante ambiental potencial. O objetivo deste trabalho foi avaliar as alterações de atributos químicos do solo, teores foliares das culturas de soja e milho segunda safra após aplicação de diferentes doses de ARS. O experimento foi conduzido em Latossolo Vermelho, sob sistema de plantio direto, no Centro de Pesquisa Cooperativa Agroindustrial Consolata. Foi utilizado o delineamento de blocos casualizados com parcelas subdivididas, sendo aplicadas nas parcelas principais diferentes doses de 0, 35, 70,105 e $140 \mathrm{~m}^{3} \mathrm{ha}^{-1}$ ano $^{-1}$ de ARS e, nas sub parcelas, dois níveis de adubação mineral (ausência e presença), para a soja aplicou-se $300 \mathrm{~kg} \mathrm{ha}^{-1}$ da formulação 04-2416 no momento da semeadura e para o milho segunda safra, $300 \mathrm{~kg} \mathrm{ha}^{-1}$ de la formulación 10 15-15 no período do experimento, compreendido de setembro de 2013 a agosto de2014. Após a colheita do milho segunda safra, amostras de solo nas camadas de 0-0,10 e 0,10-0,20 m foram realizadas, determinando-se el tenor de carbono orgânico, $\mathrm{P}, \mathrm{K}, \mathrm{Cu}$ e Zn, além da determinação dos teores foliares de N, P, K, Cu e Zn das culturas de soja e milho segunda safra. A aplicação de ARS aumenta os níveis de P nas camadas 0-0,10 e 0,10-0,20 me nos teores foliares da cultura da soja, demonstrando que os nutrientes presentes na ARS podem ser aproveitados pelas culturas.

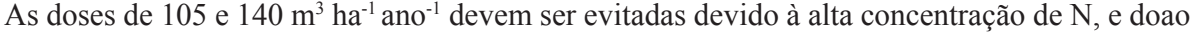
aumento dos teores de $\mathrm{P}$ em concentrações que constituem risco ambiental. 


\section{INTRODUCCIÓN}

La suinocultura industrial conjuntamente con otras cadenas productivas de agronegocios ha crecido significativamente en la última década, y con prospección de mantener ese desarrollo en los próximos años (ABIPECS, 2015).

Además de incrementar la rentabilidad de productores empleando mano de obra familiar, existe la posibilidad de utilizar el ARS como abono orgánico, a fin de reducir costos de producción de pequeñas propiedades rurales (FACTOR et al., 2008; FRIGO et al., 2006; GATIBONI et al., 2008).

La suinocultura se desarrolla generalmente en pequeñas propiedades de escasas extensiones de tierras, con la característica de concentrar una alta cantidad de nutrientes presentes en el ARS, que pueden tornarse contaminante del suelo, aire y agua (BERTONCINI, 2011; GATIBONI et al., 2008), sobre todo cuando son utilizados sin criterios técnicos, lo que ocasiona un nulo aprovechamiento por los cultivos en los sistemas de producción.

En este sentido, existe la preocupación ambiental por las cargas poluentes de ARS cuando es utilizado en altas dosis, que pueden provocar percolación de fósforo $(\mathrm{P})$ y causar eutrofización, así como volatilización, lixiviación y escurrimiento de nitrógeno $(\mathrm{N})$ para cursos de agua (MORI et al., 2009), cuando son realizadas aplicaciones continuas de ARS (KUNZ et al., 2005), además de poseer elevada concentración de metales pesados, como cobre $(\mathrm{Cu})$ y zinc $(\mathrm{Zn})$, que pueden causar fitotoxicidad en plantas y contaminar productos agrícolas (GIROTTO, 2010; HERNANDEZ et al., 2006).

El ARS, cuando utilizada de manera equilibrada, puede traer beneficios, surgiendo la necesidad de identificar dosis adecuadas para cada sistema de cultivo y de acuerdo con las condiciones del suelo y del clima de cada región. En este sentido, PEREIRA (2011) menciona que antes de definir dosis de abonos orgánicos a ser aplicados, deben conducirse experimentaciones previas considerando se el sistema de cultivo utilizado, el régimen de precipitaciones, la época, la disponibilidad de residuos, entre otros.

LOURENZI (2011) afirma que todo residuo orgánico adicionado al suelo debe ser evaluado en parámetros cualitativos, bien como en aspectos pertinentes al balance de la materia orgánica del suelo. Además, menciona que las aplicaciones de ARS en los sistemas de cultivos de siembra directa, representan una adición de carbono orgánico al suelo, pudiendo representar variaciones en la materia orgánica, no sobre el punto de vista cuantitativo, sino más bien cualitativo.

Desde este contexto, la viabilidad económica de la suinocultura puede estar comprometida, pues la atención de diversos sectores de la sociedad hacia la necesidad de un mayor desarrollo tecnológico respecto a residuos generados por animales viene aumentando significativamente, procurando un mínimo impacto sobre recursos naturales, ya que los consumidores buscan una sustentabilidad en los productos (CASSOl et al., 2012).

Toda la producción de la cadena suinicola precisa establecer un mayor énfasis, no sólo en las exigencias del mercado consumidor, sino también en la sociedad entera, sin que se vea afectada la perpetuación de especies en el planeta (CRUSCIOL et al., 2008). Sin embargo, a pesar de una gran cantidad de residuos producidos dentro de esta cadena, la población puede ser beneficiada con una utilización eficiente de nutrientes contenidos en el ARS.

Las ARS provenientes de lagunas de estabilizaciónanaeróbica(local dealmacenamiento) poseen $60 \%$ de $\mathrm{N}$ en la forma amoniacal $\left(\mathrm{NH}_{4}^{+}\right)$ (SCHERER et al., 1996). AITA y GIACOMINI (2008) mencionan que la velocidad con que este $\mathrm{N}$ amoniacal es nitrificado en el suelo y el destino del $\mathrm{NO}_{3}{ }^{-}$son de extrema importancia, no sólo para un conocimiento de aprovechamiento por los cultivos, sino también relacionado a su comportamiento en el ambiente.

En la producción de granos, el N normalmente es el nutriente que representa un mayor gasto económico, y tiene una alta movilidad en el sistema suelo-planta-atmosfera, donde las relaciones que ocurren en el suelo son mediadas por microorganismos, cuya actividad es afectada principalmente por temperatura y humedad, por lo que un manejo correcto de este elemento acarrea implicaciones económicas y ambientales, al utilizar dosis excesivas en función a las aprovechadas por los cultivos (AITA et al., 2007). 
En este sentido, determinar las respuestas que se obtienen con la adición de ARS nos permite calcular adecuadamente la dosis a ser aplicada. Por tal, el objetivo de este trabajo fue evaluar las alteraciones de atributos químicos de un Rhodic Kandiudox, y los tenores foliares de N, P, K, Cu y Zn en los cultivos de soja y maíz segunda zafra, en función de la aplicación de agua residual de suinocultura asociada a fertilizante mineral en un sistema de siembra directa.

\section{METODOLOGIA}

El presenta trabajo fue conducido durante el período de octubre de 2013 a setiembre de 2014, en el Centro de Investigación de la Cooperativa Agroindustrial Consolata Copacol, ubicada en el municipio de Cafelândia, Paraná, con coordenadas de latitud $24^{\circ} 37^{\prime} 18,77^{\prime \prime} \mathrm{S}$, longitud $53^{\circ} 18^{\prime} 17,63^{\prime \prime} \mathrm{O}$, y altitud promedio de $590 \mathrm{~m}$. El suelo está clasificado como Rhodic Kandiudox, de textura arcillosa con buen drenaje natural (EMBRAPA, 2013). En el campo experimental el tenor de arcilla del suelo de la camada $0-0,20 \mathrm{~m}$ fue de $0,720 \mathrm{~g}$ $\mathrm{kg}^{-1}$.

La caracterización química del suelo fue realizada basándose en la metodología descritas por LANA et al. (2010), presentadas en la tabla 1. Se determinó tenores de $\mathrm{P}, \mathrm{K}^{+}, \mathrm{Cu}, \mathrm{Zn}, \mathrm{Fe}$ e $\mathrm{Mn}$ por Mehlich-1. Los tenores de $\mathrm{Ca}^{2+}, \mathrm{Mg}^{2+} \mathrm{e} \mathrm{Al}^{3+}$ por extracción de KCL. La materia orgánica (M.O.) por Walkey Black. El pH en $\mathrm{CaCl}_{2}$. La acidez potencial $(\mathrm{H}+\mathrm{Al})$ fue determinada por taponamiento SMP. $\mathrm{El}$ azufre $\mathrm{S}\left(\mathrm{SO}_{4}\right)^{2-}$ fue extraído con fosfato mono cálcico. El boro (B) por extractor Cloruro de Bario.

El sistema de preparación de suelo adoptado fue el de siembra directa (SSD). El manejo fitosanitario fue realizado de acuerdo a los niveles de daños económicos mediante controles químicos para plagas, enfermedades y malezas.

El ARS fue colectada de una laguna de estabilización anaeróbica proveniente de una granja de suinos situada en la región oeste de Paraná. El estiércol fue homogeneizado con un agitador mecánico que es utilizado para desechos decantados y fue colectado a una profundidad de 1,00 m. Las dosis de ARS fueron aplicadas mediante tractor con acople del tanque distribuidor en las parcelas 10 días antes de la siembra del cultivo de soja.

Los datos de temperatura máxima y mínima y de precipitación pluvial, con relación al período de duración del experimento, fueron registrados diariamente (Figura 1).

Una muestra de ARS utilizada en el experimento fue llevada al laboratorio de análisis químico y físico Solanálise, localizado en el municipio de Cascavel-Paraná, los resultados presentados se encuentran descriptos en la Tabla 2.

Tabla 1. Atributos químicos de las muestras recolectadas antes de la instalación del experimento

\begin{tabular}{|c|c|c|c|c|c|c|c|c|c|c|c|}
\hline Camada & $\mathrm{P}$ & M.O & $\mathrm{pH}$ & $\mathrm{Ca}^{+2}$ & $\mathrm{Mg}^{+2}$ & $\mathrm{~K}^{+}$ & $\mathrm{H}+\mathrm{Al}$ & $\mathrm{Al}^{+3}$ & $\mathrm{CIC}$ & SB & $\mathrm{Ca} / \mathrm{Mg}$ \\
\hline $\mathrm{m}$ & $\mathrm{mg} \mathrm{dm} \mathrm{m}^{-3}$ & $\mathrm{~g} \mathrm{dm}^{-3}$ & & \multicolumn{8}{|c|}{ 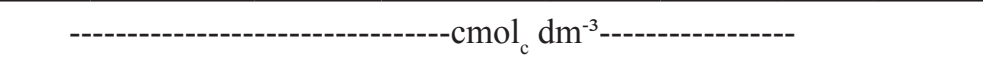 } \\
\hline $0-0,10$ & 21,10 & 23,77 & 4,60 & 5,15 & 1,44 & 0,50 & 7,20 & 0,08 & 14,29 & 7,09 & 3,58 \\
\hline $0,10-0,20$ & 13,00 & 17,14 & 4,50 & 4,48 & 1,21 & 0,34 & 7,20 & 0,19 & 13,23 & 6,03 & 3,70 \\
\hline $0-0,20$ & 17,05 & 20,46 & 4,55 & 4,82 & 1,33 & 0,42 & 7,20 & 0,14 & 13,76 & 6,56 & 3,64 \\
\hline Camada & $\mathrm{V}$ & $\mathrm{Al}$ & $\mathrm{Ca}^{+2}$ & $\mathrm{Mg}^{+2}$ & $\mathrm{~K}^{+}$ & $\mathrm{S}-\mathrm{SO}_{4}^{-2}$ & $\mathrm{~B}$ & $\mathrm{Mn}$ & $\mathrm{Zn}$ & $\mathrm{Cu}$ & $\mathrm{Fe}$ \\
\hline $\mathrm{m}$ & \multicolumn{11}{|c|}{--------------------------\%"----------------------- } \\
\hline $0-0,10$ & 49,62 & 1,12 & 36,04 & 10,08 & 3,50 & 3,75 & 0,60 & 101,00 & 13,34 & 13,47 & 15,00 \\
\hline $0,10-0,20$ & 45,58 & 3,05 & 33,86 & 9,15 & 2,57 & 5,15 & 0,55 & 93,00 & 8,64 & 15,58 & 22,00 \\
\hline $0-0,20$ & 47,60 & 2,08 & 34,95 & 9,61 & 3,03 & 4,45 & 0,57 & 97,00 & 10,99 & 14,52 & 18,50 \\
\hline
\end{tabular}

Método: $\mathrm{P}, \mathrm{K}^{+}, \mathrm{Cu}, \mathrm{Zn}, \mathrm{Fe}$ e $\mathrm{Mn}-$ Mehlich-1; $\mathrm{Ca}^{2+}, \mathrm{Mg}^{2+}$ e $\mathrm{Al}^{3+}-\mathrm{KCl} ; \mathrm{M} . \mathrm{O}$ - Walkey Black; $\mathrm{pH}$ - Cloruro de Calcio; $\mathrm{H}+\mathrm{Al}-$ Tamponamiento SMP; $\mathrm{S}\left(\mathrm{SO}_{4}\right)^{2-}$ Fosfato Monocálcico; B - Cloruro de Bario (LANA et al., 2010). 


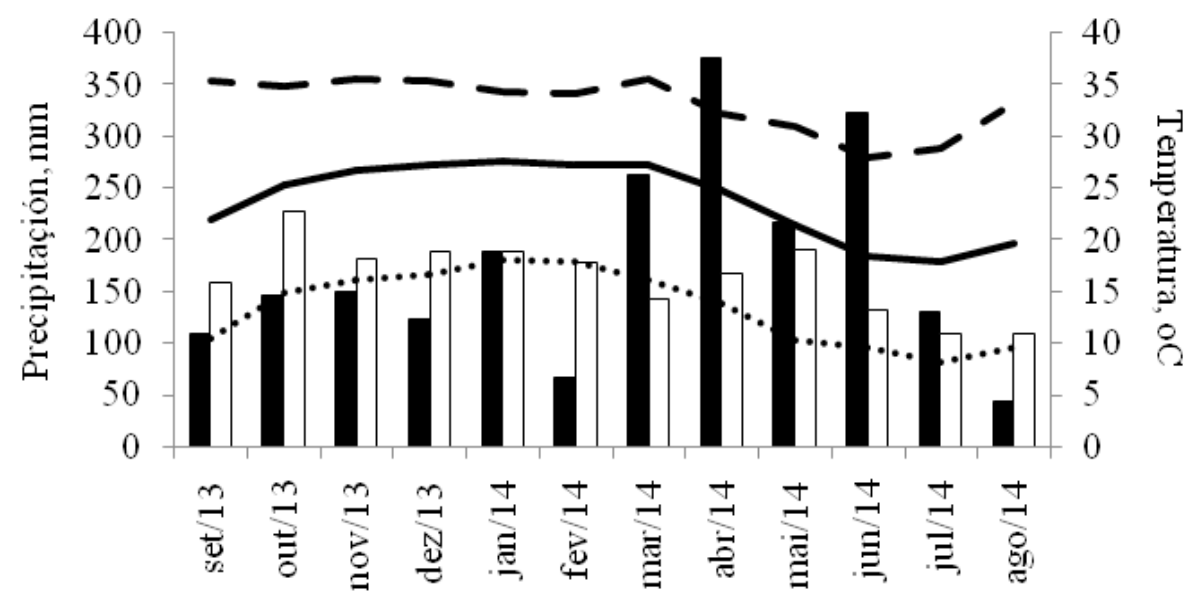

Periodo (meses)

Figura 1. Temperaturas máximas y mínimas, registradas durante período de setiembre de 2013 a agosto de 2014 en el experimento a campo.

Tabla 2. Atributos físico-químicos de agua residual de suinocultura (ARS) y cantidad de elementos químicos en función de las dosis aplicadas en el experimento

\begin{tabular}{|c|c|c|c|c|c|}
\hline \multirow{2}{*}{ Nutriente } & \multirow{2}{*}{$\mathrm{kg} \mathrm{m}^{-3}$} & \multicolumn{4}{|c|}{ Dosis aplicada $\left(\mathrm{m}^{-3} \mathrm{ha}^{-1} \mathrm{ano}^{-1}\right)$} \\
\hline & & 35 & 70 & 105 & 140 \\
\hline & & \multicolumn{4}{|c|}{ - } \\
\hline $\mathrm{N}$ & 1,91 & 66,85 & 133,7 & 200,55 & 267,4 \\
\hline $\mathrm{P}$ & 0,15 & 5,25 & 10,5 & 15,75 & 21 \\
\hline K & 4,19 & 146,65 & 293,30 & 439,95 & 586,60 \\
\hline $\mathrm{Ca}$ & 0,096 & 3,36 & 6,72 & 10,08 & 13,44 \\
\hline $\mathrm{Mg}$ & 0,064 & 2,24 & 4,48 & 6,72 & 8,96 \\
\hline S & 0,048 & 1,68 & 3,36 & 5,04 & 6,72 \\
\hline $\mathrm{C}$ & 1,24 & 43,4 & 86,8 & 130,2 & 173,60 \\
\hline \multirow[t]{2}{*}{ MO } & 2,13 & 74,55 & 148,10 & 223,65 & 298,20 \\
\hline & $\mathrm{mg} \mathrm{m}^{-3}$ & & & & \\
\hline $\mathrm{Cu}$ & 1,24 & 0,0434 & 0,0868 & 0,1302 & 0,1736 \\
\hline $\mathrm{Zn}$ & 2,84 & 0,0994 & 0,1988 & 0,2982 & 0,3976 \\
\hline $\mathrm{Fe}$ & 8,69 & 0,30415 & 0,6083 & 0,91245 & 1,2166 \\
\hline $\mathrm{Mn}$ & 1,68 & 0,0588 & 0,1176 & 0,1764 & 0,2352 \\
\hline $\mathrm{B}$ & 2,21 & 0,07735 & 0,1547 & 0,23205 & 0,3094 \\
\hline $\mathrm{pH}$ & 7,29 & & & & \\
\hline Densidad $\left(\mathrm{kg} \mathrm{m}^{-3}\right)$ & 1006 & & & & \\
\hline
\end{tabular}

El ensayo fue instalado con cinco tratamientos y cuatro repeticiones con diseño experimental de bloques al azar (DBA) con parcelas subdividas, totalizando 40 parcelas experimentales. En las parcelas principales fueron aplicadas las diferentes dosis de ARS $\left(0,35,70,135\right.$ y $140 \mathrm{~m}^{3} \mathrm{ha}^{-1}$ año1), y en las parcelas secundarias o subparcelas fue realizada la fertilización mineral (ausencia o presencia).

El cultivo de soja fue sembrado en el mes de 
setiembre de 2013 y la fertilización realizada de acuerdo a recomendación de Embrapa (2014), la fertilización mineral se efectúo en el momento de la siembra del cultivo de forma localizada en el surco, aplicándose $300 \mathrm{~kg} \mathrm{ha}^{-1}$ de la formulación 04-2416 , sembrada y fertilizada con una abonadora surcadora regulada a $0,12 \mathrm{~m}$ de profundidad estimándo una población de 300 mil semillas viables por hectárea.

Para el maíz segunda zafra sembrado en marzo de 2014 fueron aplicados $300 \mathrm{~kg} \mathrm{ha}^{-1}$ de la formulación 10-15-15 en el momento de la siembra, en el surco, y $30 \mathrm{~kg} \mathrm{ha}^{-1}$ de $\mathrm{N}$ en el estadio V4 utilizándo urea (45-0-0) como fuente nitrogenada, sembradas y fertilizadas con la misma abonadora surcadora a $0,12 \mathrm{~m}$ de profundidad y una densidad de 68 mil semillas viables por hectárea aproximadamente.

Cada parcela estuvo constituida por diez hileras para el cultivo de soja, con espaciamiento de 0,45 $\mathrm{m}$ y seis hileras para el maíz con separación de 0,80 m entre sí. Las parcelas principales tuvieron dimensiones de $13,0 \mathrm{~m}$ de largura y $11,0 \mathrm{~m}$ de anchura, con área útil en cada sub parcela de $65 \mathrm{~m}^{2}$.

Para la determinación de tenores de nitrógeno $(\mathrm{N})$, fósforo $(\mathrm{P})$, potasio $(\mathrm{K})$, cobre $(\mathrm{Cu})$ y zinc $(\mathrm{Zn})$ fueron recolectadas 10 hojas de soja al azar de cada subparcela, con peciolo, correspondiente a la $3^{\mathrm{a}} \mathrm{o}$ $4^{\mathrm{a}}$ hoja totalmente abierta considerándose desde el ápice hasta la base de la planta durante el estadio fenológico R2 (EMBRAPA, 2014).

Para el cultivo de maíz fueron recolectadas seis hojas sin considerar la vaina de cada sub parcela de manera aleatoria. La muestra foliar correspondió a la hoja ubicada abajo y opuesta a la inflorescencia femenina, situada en la base de la espiga, durante el estadio fenológico R1 (RAIJ, 2011).

Las muestras fueron acondicionadas en bolsas de papel y secadas en estufa de circulación forzada a $65^{\circ} \mathrm{C}$ por 72 horas, para posteriormente ser molidas con ayuda de molino tipo Willey en el Laboratorio de Fertilidad de Suelo y Nutrición de Plantas de la Universidad Estadual del Oeste de Paraná, situada en el municipio de Marechal Cándido RondónParaná. Los tenores de $\mathrm{N}, \mathrm{P}, \mathrm{K}, \mathrm{Cu}$ y $\mathrm{Zn}$ fueron determinados en el mismo laboratorio según metodología descrita por LANA et al. (2010).

Las muestras de suelo fueron colectadas en cada sub parcela, posterior a la cosecha del cultivo de maíz segunda zafra, con pala de corte en las profundidades de $0-0,10$ y $0,10-0,20 \mathrm{~m}$ totalizando 80 muestras de suelo.

Las muestras fueron encaminadas al laboratorio de análisis químico Santa Rita, situada en el municipio de Mamborê-Paraná. La caracterización química del suelo mediante la determinación de tenores de $\mathrm{P}, \mathrm{K}^{+}, \mathrm{Cu}, \mathrm{Zn}$ (Mehlich-1) y C orgánico (Walkey Black) fue basada en la metodología descrita por LANA et al. (2010).

Los datos obtenidos fueron sometidos a análisis de variancia. El efecto significativo de la fertilización mineral en cada variable analizada arrojó una comparación de medias por el test de Tukey al 5\% de probabilidad de error. Para los promedios de dosis de ARS fueron seleccionados modelos de regresión con base de significancia por el test $\mathrm{F}$, considerando niveles de 5 y $1 \%$ de probabilidad de error y mayor valor de coeficiente de determinación $\left(\mathrm{R}^{2}\right)$. Para los análisis estadísticos fue utilizado el programa estadístico Sisvar 5.1 (FERREIRA, 2011).

\section{RESULTADOS}

Los tenores de $\mathrm{P}, \mathrm{K}, \mathrm{Cu}$ y $\mathrm{Zn}$ disponibles en la camada $0-0,10 \mathrm{~m}$ presentaron efectos significativos $(\mathrm{p}<0,01)$ a la aplicación de ARS, sin embrago, no hubo interacción con relación a la fertilización mineral. Solamente el C orgánico no fue influenciado significativamente con la adición de ARS.

El contenido de $\mathrm{P}$ en el suelo aumentó linealmente a la aplicación de ARS, con aumentos de $0,44 \mathrm{mg} \mathrm{dm}^{-3}$ de P por cada metro cubico de ARS aplicado (Figura 2A), adicionadas anteriormente a los cultivo de soja y maíz segunda zafra. El ARS presenta altas concentraciones de $\mathrm{P}$, que, además de ser aplicado superficialmente sin incorporación al suelo, contribuyó para elevar sus niveles (CERETTA et al., 2010; SCHERER et al., 2007).

Los datos encontrados en este experimento indican que el ARS en dosis altas (105 e $140 \mathrm{~m}^{3} \mathrm{ha}^{-1}$ año ${ }^{-1}$ ) representa un desperdicio en la fertilización con P.

Según el resultado de análisis de suelo del área donde fue realizado el experimento (Cuadro 1), la 
dosis máxima de ARS para un tenor de P que no sobrepase la clase considerada muy alta (42 $\mathrm{mg} \mathrm{kg}$ $\left.{ }^{1}\right)$ en la camada de $0-0,10 \mathrm{~m}$ con tenor de argila superior a $600 \mathrm{~g} \mathrm{~kg}^{-1}$ sería de $30 \mathrm{~m}^{3} \mathrm{ha}^{-1} \mathrm{año}^{-1}$, a fin de evitar posibles pérdidas por exceso de dosis del fertilizante, además de posibles problemas de contaminación del ambiente por acumulación de fosfatos (SBCS-CQFS-RS/SC, 2004).
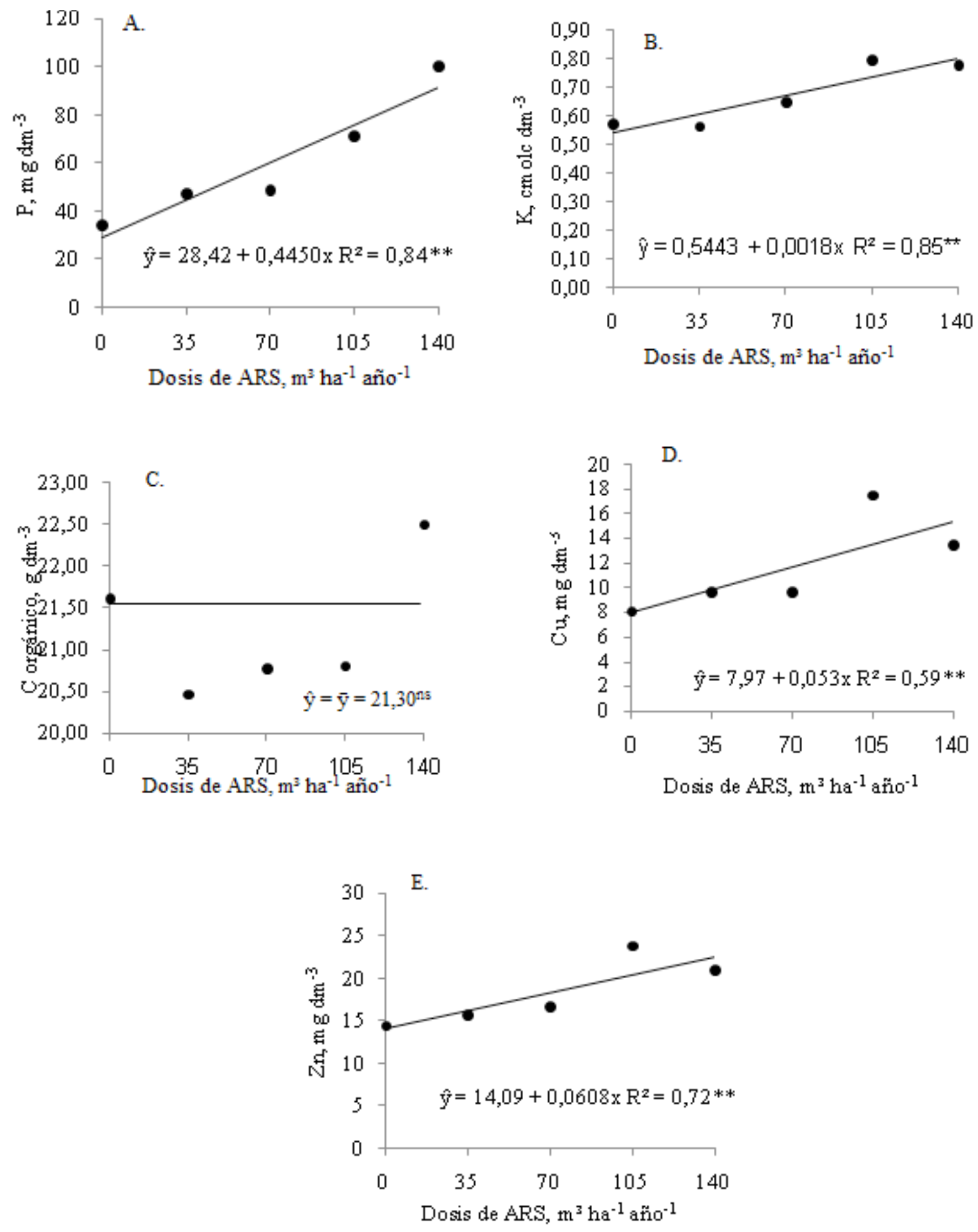

${ }^{\mathrm{ns}}$ no significativo, *significativo $(\mathrm{p}<0,05)$ e ${ }^{* *}$ significativo $(\mathrm{p}<0,01)$.

Figura 2. Tenores de fósforo (A), potasio (B), carbono orgánico (C), cobre (D) e zinc (E), en la camada de $0-0,10 \mathrm{~m}$ posterior a aplicación anual de ARS. 
Los tenores de K na camada de 0-0,10 m también aumentaron linealmente en función de las dosis de ARS aplicadas (Figura 2B). La utilización de $35 \mathrm{~m}^{3}$ $\mathrm{ha}^{-1}$ de ARS por año permitió la manutención de los tenores iniciales de $\mathrm{K}$ en el suelo.

Las dosis de 0 a $140 \mathrm{~m}^{3}$ ha $^{-1}$ año $^{-1}$ de ARS aplicadas ocasionaron aumentos en los tenores de $\mathrm{K}$ en el suelo en la profundidad de $0-0,10 \mathrm{~m}$, con variación de 0,57 a $0,78 \mathrm{cmol}_{\mathrm{c}} \mathrm{dm}^{-3}$. Considerándose que el ARS utilizada en el experimento contribuyó con 4,19 $\mathrm{kg} \mathrm{m}^{-3} \mathrm{de} \mathrm{K}$, en relación a la dosis más alta $\left(140 \mathrm{~m}^{3} \mathrm{ha}^{-1}\right.$ año $\left.^{-1}\right)$ totalizó una cantidad anual de $586,60 \mathrm{~kg} \mathrm{ha}^{-1}$ de K (Tabla 2).

A fin de garantizar productividades de $5,0 \mathrm{t}$ ha ${ }^{-1}$ de soja y 6,0 t ha ${ }^{-1}$ de maíz, considerándose el tenor de $\mathrm{K}^{+}$encontrado en el análisis de suelo de la camada $0-0,20 \mathrm{~m}$, que fue de $0,42 \mathrm{cmol}_{\mathrm{c}} \mathrm{dm}^{-3}$ (Tabla 1), serían necesarias aplicaciones de $150 \mathrm{y}$ $70 \mathrm{~kg} \mathrm{ha}^{-1}$ de $\mathrm{K}_{2} 0$ respectivamente (SBCS-CQFS$\mathrm{RS} / \mathrm{SC}, 2004)$. De tal modo que en dos cultivos, uno de soja y otro de maíz segunda zafra, seria recomendada la aplicación de $220 \mathrm{~kg} \mathrm{ha}^{-1} \mathrm{~K}_{2} \mathrm{O}$ $182,63 \mathrm{~kg} \mathrm{ha}^{-1}$ de $\mathrm{K}$.

Con la adición de 43,58 $\mathrm{m}^{3}$ ha $^{-1}$ año-1 serían suplidas las necesidades de $\mathrm{K}$ en los cultivos de soja y maíz, considerándose que el ARS utilizada en el experimento contiene $4,13 \mathrm{~kg} \mathrm{~m}^{3}$ de $\mathrm{K}$ (Tabla 2), estando $100 \%$ disponible en el primer cultivo (SBCS-CQFS-RS/SC, 2004).

LOURENZI (2011), en un Rhodic Paleudult, aplicando dosis de hasta $80 \mathrm{~m}^{3}$ ha ${ }^{-1}$ año-1e ARS con concentraciones de $\mathrm{P}$ y $\mathrm{K}$ que variaron entre $1,50 \mathrm{a}$ $2,40 \mathrm{~kg} \mathrm{~m}^{-3}$, y 0,41 a $1,30 \mathrm{~kg} \mathrm{~m}^{-3}$ respectivamente, entre los años 2000 a 2008, comprobó aumentos en los tenores de $\mathrm{P}$ disponible y $\mathrm{K}$ intercambiable hasta la camada de $0,60 \mathrm{~m}, \mathrm{y}$ de $\mathrm{P}$ total hasta 0,30 $\mathrm{m}$ de profundidad, proporcionando un ambiente más adecuado para el desarrollo radicular de las plantas.

Las aplicaciones de ARS no aumentaron el carbono orgánico en la camada superficial, siendo que los valores encontrados en los tratamientos no demostraron diferencias significativas, con tenores de $C$ con escasa variación, siendo que la alteración de esta propiedad fue de apenas de 20,50 a 22,50 $\mathrm{g} \mathrm{dm}^{-3}$, como razón probable se tiene el bajo tenor de carbono y materia orgánica contenida en el estiércol (Figura 2C). Se puede destacar que en ninguna parcela hubo reducción de los tenores de $\mathrm{C}$ orgánico, con lo que se comprueba que la aplicación de ARS ayuda a mantener las cantidades de $\mathrm{C}$ orgánico en el suelo. En este sentido, según
SBCS-CQFS-RS/SC (2004), el sistema de siembra directa asociado a sistemas con adición de residuos orgánicos, resulta en un balance positivo de $\mathrm{MO}$ en el suelo.

Las concentraciones de $\mathrm{Cu}$ e $\mathrm{Zn}$ aumentaron linealmente con la aplicación de ARS en la camada superficial del suelo, donde por cada $1 \mathrm{~m}^{3}$ ha $^{-1}$ año ${ }^{-1}$ hubo un aumento de 0,053 y $0,060 \mathrm{mg}$ $\mathrm{dm}^{-3}$ en la camada de 0-0,10 m (Figura 2D e 2E) para $\mathrm{Cu}$ y $\mathrm{Zn}$, respectivamente. JONDREVILLE et al. (2003) y SMANHOTTO et al. (2010) recomiendan aplicaciones de $\mathrm{Cu}$ y $\mathrm{Zn}$ en pequeñas cantidades con finalidad de prevenir enfermedades y mejorar procesos digestivos a fin de promover el crecimiento de suinos.

BASSO et al. (2012) concluyeron que 69\% de las muestras correspondientes a 13 áreas productivas de la región oeste de Santa Catarina, presentaron tenores mayores de $\mathrm{Cu}$ y $\mathrm{Zn}$ en áreas que recibían aplicaciones anuales de ARS, notándose una acumulación de esos metales en las camadas superficiales con el transcurrir de años.

Fueron adicionados $0,04,0,08,0,13$ y 0,17 $\mathrm{kg} \mathrm{ha}^{-1}$ de $\mathrm{Cu}, \mathrm{y}, 0,09,0,19,0,29$ y $0,39 \mathrm{~kg} \mathrm{ha}^{-1}$ de Zn (Cuadro 2), en dosis de ARS de 35, 70, 105 y $140 \mathrm{~m}^{3}$ ha $^{-1}$ ano $^{-1}$. Según la resolución 375 del CONAMA (2006), la aplicación de 137 y 445 $\mathrm{kg} \mathrm{ha}^{-1}$ representan los límites máximos para $\mathrm{Cu}$ y $\mathrm{Zn}$, respectivamente, en este experimento las dosis de ARS se encontraron muy bajas para ser consideradas como contaminantes en el ambiente.

Sin embargo, GIROTTO (2006) destaca la importancia de realizar estudios regionalizados para la determinación de tenores críticos de $\mathrm{Cu}$ y $\mathrm{Zn}$, pues las cargas máximas de esos metales dentro de las normativas de USEPA (1993) y CONAMA (2006) no son considerados el tipo de suelo, sistemas de cultivos, así como interacciones con las fracciones orgánicas y minerales del suelo.

Pudo observarse comportamiento significativo linear $(p<0,01)$ en los tenores de $\mathrm{P}$ en la camada $0,10-0,20 \mathrm{~m}$ del suelo en relación a aplicación de ARS. Por cada $1 \mathrm{~m}^{3} \mathrm{ha}^{-1}$ año ${ }^{-1}$, hubo un aumento de $0,0151 \mathrm{mg} \mathrm{dm}^{-3}$ de P (Figura 3A).

SCHERER et al. (2007) mencionan que la preservación de las características físicas del suelo, principalmente las observadas en el SSD, es fundamental, relacionado a la formación de canales por actividad de raíces en descomposición o biológica, acompañados por tenores adecuados de $\mathrm{MO}$ en las camadas superficiales, permiten una mayor infiltración de agua, que facilita el transporte 

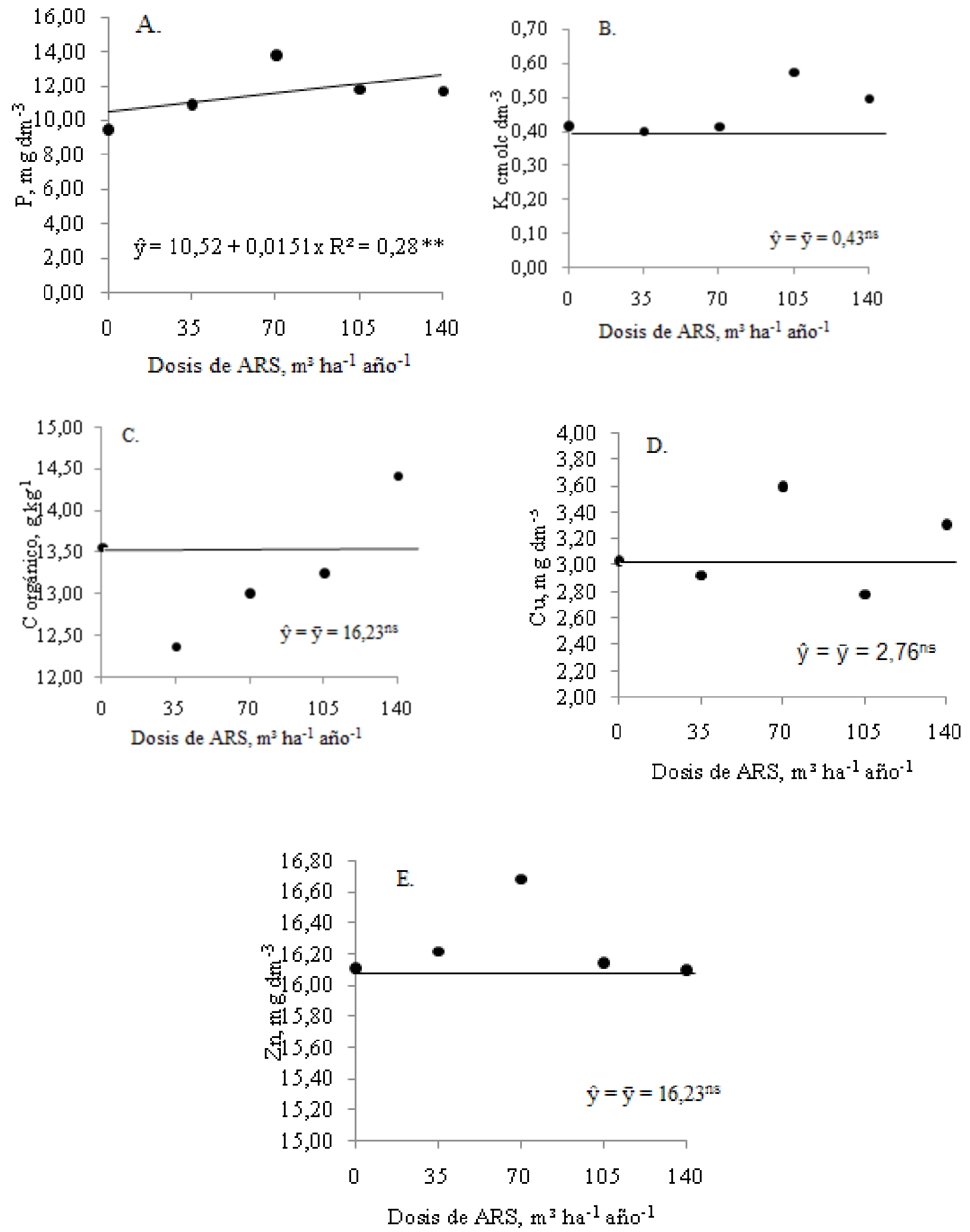

${ }^{\mathrm{NS}}$ no significativo, ${ }^{*}$ significativo $(\mathrm{p}<0,05) \mathrm{y} * *$ significantivo $(\mathrm{p}<0,01)$.

Figura 3. Tenores de fósforo (A), potasio (B), carbono orgánico (C), cobre (D) y zinc (E), en la camada de 0,10-0,20 $\mathrm{m}$ posterior a la aplicación anual de ARS. 
de solutos resultantes de la descomposición de residuos orgánicos de ARS, disminuyendo su capacidad de adsorción, además de debilitar la energía de ligación del fosfato a los grupos funcionales de coloides del suelo, ocurriendo movilidad de $\mathrm{P}$ de la camada $0-0,10$ m para la $0,10-$ $0,20 \mathrm{~m}$.

Los tenores de $\mathrm{C}$ orgánico, $\mathrm{K}, \mathrm{Cu}$ y $\mathrm{Zn}$ no presentaron variaciones significativas en esta camada de acuerdo a los datos obtenidos. ASSMANN et al. (2007), en Oxisol de Paraná, aplicando 20, 40 y $80 \mathrm{~m}^{3} \mathrm{ha}^{-1}$ año-1 de ARS a los 48 y 116 días después de la emergencia de avena negra y azeven, obtuvieron incrementos de $\mathrm{K}$, apenas en la camada 0-0,05 $\mathrm{m}$ de profundidad. Según los mismos autores, el $\mathrm{K}$ es el macronutriente menos abundante en el ARS, dependiendo directamente de la cantidad de materia seca (MS) del residuo a tasa disponible. Esta afirmación no concuerda con el resultado observado en el presente experimento, el $\mathrm{K}$ observado en el ARS es el macronutriente más abundante, en este experimento los tenores de MS fueron de 21 y $41 \mathrm{~kg} \mathrm{~m}^{3}$, en la primera y segunda aplicación respectivamente. En el presente experimento, entretanto, el elemento más cuantioso fue el $\mathrm{K}$, debido al tenor de materia seca de ARS utilizada en el experimento ser de $50 \mathrm{~kg}$ $\mathrm{m}^{3}$, valor este, $58 \%$ mayor que el tenor de MS del ARS empleada por ASSMANN et al. (2007), en la primera aplicación de su experimento.

Sin embargo, la fertilización mineral promovió un aumento en los tenores de $\mathrm{P}$ y $\mathrm{Cu}$ en la camada de 0,10- 0,20 m (Tabla 3). Para el $\mathrm{Cu}$ hubo un aumento significativo $(\mathrm{p}<0,05)$ por el test de Tukey, obteniéndose valores de 2,43 y 3,66 en ausencia y presencia de la fertilización mineral, respectivamente. GIROTTO (2010) afirma que el ion $\mathrm{Cu} 2+$ es bastante móvil en suelos ácidos, formando compuestos solubles con la mayoría de los aniones presentes en solución, además de las rocas en formación que contienen cobre, generalmente presentan relación con los tenores del suelo.

El tenor de $\mathrm{P}$ presentó significancia $(\mathrm{p}<0,05)$ por test de Tukey, en presencia de fertilización mineral, con aumentos para 21,84 y $17,58 \mathrm{mg} \mathrm{dm}^{-3}$, en las dosis de 70 y $105 \mathrm{~m}^{3}$ ha $^{-1} \mathrm{año}^{-1}$, respectivamente. De modo similar, cuando fue comparado el promedio total de valores para el factor de variación en presencia y ausencia de la fertilización mineral hubo aumento en el contenido de $\mathrm{P}$ en la camada 0,10$0,20 \mathrm{~m}$. Este comportamiento puede ser atribuido al hecho de que en ocasión de la siembra de soja y maíz, para la distribución del fertilizante mineral de forma localizada, fue utilizada una abonadora surcadora de 0,12 $\mathrm{m}$ de profundidad. Según PAULETTI et al. (2008), las diferentes formas de aplicación de fertilizantes minerales, aumentan la variabilidad de los tenores de nutrientes, sobre todo horizontal, principalmente para $\mathrm{P}$, cuando los mismos son aplicados en la línea de siembra.

En la camada de 0,10-0,20 m cuando fue aplicado fertilizante mineral, lo que provocó una mayor disponibilidad de P, sin embargo, BERTHRONG et al. (2013) mencionan que la fertilización orgánica trae consigo mayores beneficios que la fertilización mineral, ocasionando una mayor diversidad en la comunidad microbiana, aumentando fracciones de $\mathrm{C}$, mayor eficiencia en términos de respiración por unidades de $\mathrm{C}$ en el suelo.

Tabla 3. Tenores de fósforo y cobre en la camada $0,10-0,20 \mathrm{~m}$, posterior a la aplicación de dosis de ARS y fertilización mineral

\begin{tabular}{|c|c|c|c|c|c|c|c|}
\hline \multirow{2}{*}{ Nutriente } & \multirow{2}{*}{$\begin{array}{c}\text { Fertilización } \\
\text { mineral }\end{array}$} & \multicolumn{5}{|c|}{ Dosis de ARS $\left(\mathrm{m}^{3} \mathrm{ha}^{-1} \mathrm{año}^{-1}\right)$} & \multirow{2}{*}{ Promedio $^{2}$} \\
\hline & & 0 & 35 & 70 & 105 & 140 & \\
\hline & & $--\cdot$ & $-\cdots--$ & $\mathrm{mg} \mathrm{dm}^{-3}$ & & --- & \\
\hline \multirow{2}{*}{$\mathrm{P}^{1}$} & ausencia & $6,32 \mathrm{a}$ & $10,45 \mathrm{a}$ & $5,81 \mathrm{a}$ & $6,08 \mathrm{a}$ & $7,47 \mathrm{a}$ & $7,32 \mathrm{a}$ \\
\hline & presencia & $12,77 \mathrm{a}$ & $11,42 \mathrm{a}$ & $21,84 \mathrm{~b}$ & $17,58 \mathrm{~b}$ & $16,00 \mathrm{a}$ & $15,92 \mathrm{~b}$ \\
\hline \multirow{2}{*}{$\mathrm{Cu}^{1}$} & ausencia & $2,49 \mathrm{a}$ & $2,40 \mathrm{a}$ & $2,61 \mathrm{a}$ & $1,79 \mathrm{a}$ & $2,89 \mathrm{a}$ & $2,43 \mathrm{a}$ \\
\hline & presencia & $3,59 \mathrm{a}$ & $3,45 \mathrm{a}$ & $4,60 \mathrm{a}$ & $3,77 \mathrm{a}$ & $2,91 \mathrm{a}$ & $3,66 \mathrm{~b}$ \\
\hline
\end{tabular}

Promedios seguidos por la misma letra en la columna no difieren entre sí por el test de Tukey $(\alpha=0,05)$. Significativo a $5 \%$ de error.1DMS: 10,32 para $\mathrm{P}$ y 2,02 para $\mathrm{Cu}$ (4 repeticiones). 2DMS 4,61 para P y 0,90 para $\mathrm{Cu}$ (20 repeticiones). 
Aplicaciones anuales sucesivas de ARS aumentan los tenores de $\mathrm{P}$ en los sistemas de producción, pudiendo ser reciclado vía ARS, principalmente en suelos brasileros que poseen escasa disponibilidad del elemento, generalmente por fijado por acción de hierro $\left(\mathrm{Fe}^{+3}\right)$ y aluminio $\left(\mathrm{Al}^{+3}\right)$, que tornan al $\mathrm{P}$ complexado e indisponible para los vegetales, en contrapartida, un exceso también se torna preocupante desde el punto de vista ambiental, cuando el mismo se transporta a lugares de yacimiento de aguas superficiales (BERWANGER et al., 2008). Los dos factores que mayormente contribuyen a una alta disponibilidad de $\mathrm{P}$ en el ambiente son la concentración de $\mathrm{N}$ en relación al $\mathrm{P}$ contendido en el ARS, que puede variar de 2:1 a 6:1 y la tasa de exportación de cultivos, generalmente encontrada entre 7:1 a 11:1 (Sharpley et al., 1996).

De acuerdo con BARNETT (1994), cerca de $54,7 \%$ de la cantidad total de Pen laARS se encuentra en forma inorgánica y la restante en forma orgánica, conteniendo $29,7 \%$ de hexafosfato de inositol, $15,2 \%$ de ácidos nucleicos y $0,4 \%$ de fosfolípidos. Desde esta forma posterior a la aplicación de ARS, la acumulación de P normalmente es encontrada en las fracciones inorgánicas, constatados por algunos estudios sobre fracciones e acumulación de $\mathrm{P}$ en el suelo, realizados en Brasil (CERETTA, 2010), mediante técnicas de fraccionamiento propuestas por HEDLEY et al. (1982).

Conforme las Figuras 3e y $3 \mathrm{~d}$, no hubo movilidad de $\mathrm{Zn}$ y $\mathrm{Cu}$ en el perfil del suelo. GIROTTO et al. (2010), afirman que las ligaciones de $\mathrm{Cu}$ y $\mathrm{Zn}$ son principalmente químicas con alto grado de energía, pudiendo ser encontrados en las fracciones orgánicas e inorgánicas, consecuentemente con disponibilidad muy baja en la solución del suelo, sobre todo en aquellos que poseen abundancia de óxidos de Fe y manganeso (Mn), con elevada concentración de protones y alta fuerza iónica.

Los mismos autores en un experimento con ARS observaron aumentos en tenores de $\mathrm{Cu}$ y $\mathrm{Zn}$ hasta profundidades de $0,10 \mathrm{~m}$ y $0,12 \mathrm{~m}$ respectivamente en el suelo, solamente después de 17 aplicaciones sucesivas, posterior a 78 meses.

Estudios de calibración de dosis de ARS, a fin de recomendar cantidades adecuadas son importantes no solamente con el objetivo de disminuir la sobrecarga de nutrientes en el suelo, que ocasionan problemas ambientales, sino más bien debe trazarse un objetivo de alcanzar una viabilidad económica en los sistemas de producción de plantas. BLESH y DRINKWATER (2013), en un estudio realizado en una cuenca del rio Missisipi, en el cual sumaron saldos de aplicaciones de $\mathrm{N}$ durante cinco años, en base a cálculos realizados en diferentes áreas de producción mediante datos colectados a partir de entrevistas personales con 95 productores de cultivos de granos de los estados de Iowa, Ohio, Minnesota y Wisconsin, identificaron procesos de lixiviación de $\mathrm{N}$ en el suelo, demostrando una necesidad de uso de $\mathrm{N}$ de forma racional y eficiente.

Los tenores foliares de N, P, K y Zn presentaron valores altos en el cultivo de soja. Solamente el tenor foliar de $\mathrm{Cu}$ fue considerado bajo, sin embargo durante el ciclo de desarrollo de cultivo no fueron observados síntomas de toxicidad o deficiencia en la planta por el uso del estiércol (EMBRAPA, 2014).

A pesar que las dosis de ARS utilizadas en el experimento presentaron cantidades crecientes de $\mathrm{N}$, los tenores foliares no presentaron significancia $(\mathrm{p}<0,05)$, posiblemente debido a la volatilización de $\mathrm{N}$ ocurrida en el ARS.

BASSO et al. (2004) estudiaron pérdidas por volatilización de $\mathrm{N}$ contenido en el ARS aplicando dosis hasta $80 \mathrm{~m}^{3} \mathrm{ha}^{-1}$, en cuatro meses: febrero, mayo, octubre y diciembre, evaluaron dosis bajas de ARS con la finalidad de minimizar pérdidas de $\mathrm{N}$ por volatilización de amonio.

Los mismos autores concluyeron que las mayores pérdidas de $\mathrm{N}$ por volatilización ocurrieron en los meses de diciembre y febrero, debido a las mayores temperaturas registradas durante esos periodos. Temperaturas superiores a $30{ }^{\circ} \mathrm{C}$ favorecen la descomposición del estiércol en las unidades de fermentación e/o almacenamiento, proporcionando mayores cantidades de $\mathrm{N}$ mineral $\left(\mathrm{NH}_{4}^{+}\right)$en relación al $\mathrm{N}$ total. Al mismo tiempo, se puede destacar que cuando el ARS fue aplicado en el mes de octubre, por más que el mismo presentó un mayor contenido de MS en relación a otros meses aplicados, hubo menores concentraciones 
de $\mathrm{N}$ mineral y menos volatilización, debido a menores temperaturas promedio ocurridas en este mes, comparadas a febrero y diciembre.

La alta respuesta en los tenores de $\mathrm{K}$ en el cultivo de soja, sin embargo no significativa, puede estar relacionada al histórico del área. El tenor inicial de $\mathrm{K}$ en el experimento fue de nivel alto (Tabla 1), acompañado de que el suelo acumuló gran volumen de rastrojos de maíz que correspondieron al cultivo anterior (antes de la implantación del experimento) que pudieron liberar cantidades desiguales de $\mathrm{K}$, con variaciones entre 7 a $24 \mathrm{~kg} \mathrm{ha}^{-1}$ (ROSOLEM et al., 2003).

En contrapartida los tenores foliares de $\mathrm{P}$ en la soja, fue observada respuesta linear (Figura 04), con aumento de $0,0028 \mathrm{~g} \mathrm{~kg}^{-1}$ por cada $\mathrm{m}^{3} \mathrm{ha}^{-1}$ año $^{-}$ ${ }^{1}$ de ARS aplicado, con variación de 3,55 a 3,96 g $\mathrm{kg}^{-1}$ para las dosis de 0 a $140 \mathrm{~m}^{3} \mathrm{ha}^{-1}$ año ${ }^{-1}$ de ARS, respectivamente, evidenciando que los mismos fueron considerados suficientes o adecuados para el cultivo.

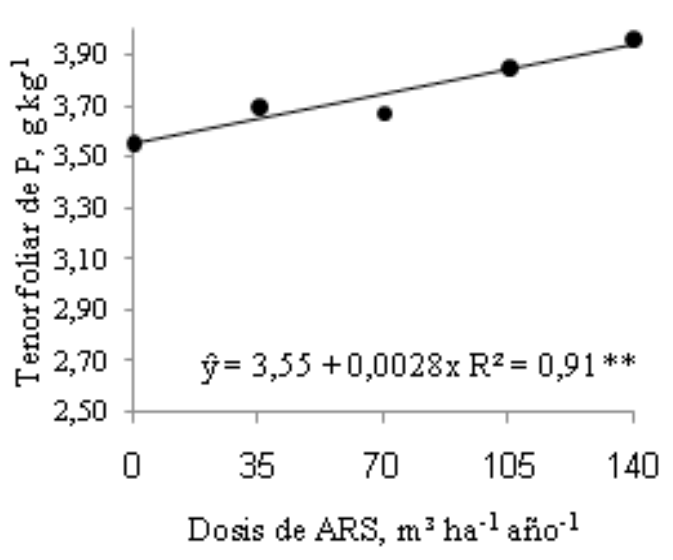

*significantivo $(\mathrm{p}<0,05)$ y **significantivo $(\mathrm{p}<0,01)$.

Figura 4. Dosis de agua residual de suinocultura, para tenores foliares de fósforo en el cultivo de soja.

Este resultado demuestra eficiencia en el proceso de reciclaje, aprovechamiento y neutralización de P por la planta, proveniente del ARS, debido a que las fuentes minerales resultan finitas (FIXEN, 2010). El fósforo representa un desafío de gestión, pues rápidamente se están agotando las reservas de este recurso esencial y no renovable.
Al mismo tiempo, su exceso puede llevar a una contaminación de ecosistemas acuáticos. SHIPANSKI y BENNETT et al. (2012) han demostrado preocupación con relación al posible reciclaje de fósforo por el uso de estiércol suino. Actualmente, existen tendencias para un mayor consumo de $\mathrm{P}$, debido al crecimiento del comercio agrícola y aumento de concentración de sistemas de producción animal, como consecuencia del alto consumo de carnes y derivados por parte de la sociedad, que pueden influenciar en la distribución de este nutriente en la superficie terrestre.

BERWABGER et al. (2006), al estudiar la influencia de dosis de $0,20,40$ e $80 \mathrm{~m}^{3} \mathrm{ha}^{-1}$ de ARS en un Argissolo Distrofico Utissol sobre la acumulación de $\mathrm{P}$ en el suelo durante cinco años, constataron que la capacidad máxima de absorción es constante a la energía relacionada a la ligación de $\mathrm{P}$, disminuidas con el aumento de las cantidades acumuladas de ARS, aumentando así su concentración de equilibrio en el suelo.

En el cultivo de maíz segunda zafra, los tenores foliares de N, P y K no fueron alterados con la aplicación de dosis de ARS. Sin embargo, para Cu, hubo aumento de $0,04 \mathrm{mg} \mathrm{kg}^{-1}$, a cada $\mathrm{m}^{3}$ ha $^{-1}$ año${ }^{1}$ aplicado (Figura 5A). Para Zn, hubo interacción entre las dosis de ARS y complementación con fertilización mineral (Figura 5B).

HERNANDEZ et al. (2006), estudiaron el comportamiento de $\mathrm{Cu}$ y $\mathrm{Zn}$ en el suelo, aplicando dosis de ARS de 0 a $90 \mathrm{~m}^{3} \mathrm{ha}^{-1}$ año-1 durante 7 años, verificando una disminución en la afinidad de estos nutrientes por consecuencia de ácidos húmicos, o sea, aumentaron la disponibilidad de $\mathrm{Cu}$ y $\mathrm{Zn}$ en el suelo, pudiendo causar fitotoxicidad a las plantas. Entretanto, los tenores de $\mathrm{Cu}$ y $\mathrm{Z}$ fueron considerados adecuados, no siendo constatados síntomas de deficiencia o toxicidad en las plantas de maíz (BORGHI et al, 2004; MARTINEZ, 1999).

Síntomas de toxicidad de $\mathrm{Cu}$ no son comunes, mismo cuando el elemento es encontrado en cantidades excesivas en el suelo. Sin embargo, cuando un síntoma aparece, sobre todo en los estadios iniciales del cultivo, es la reducción en el crecimiento de los mismos (GUPTA, 2001). 

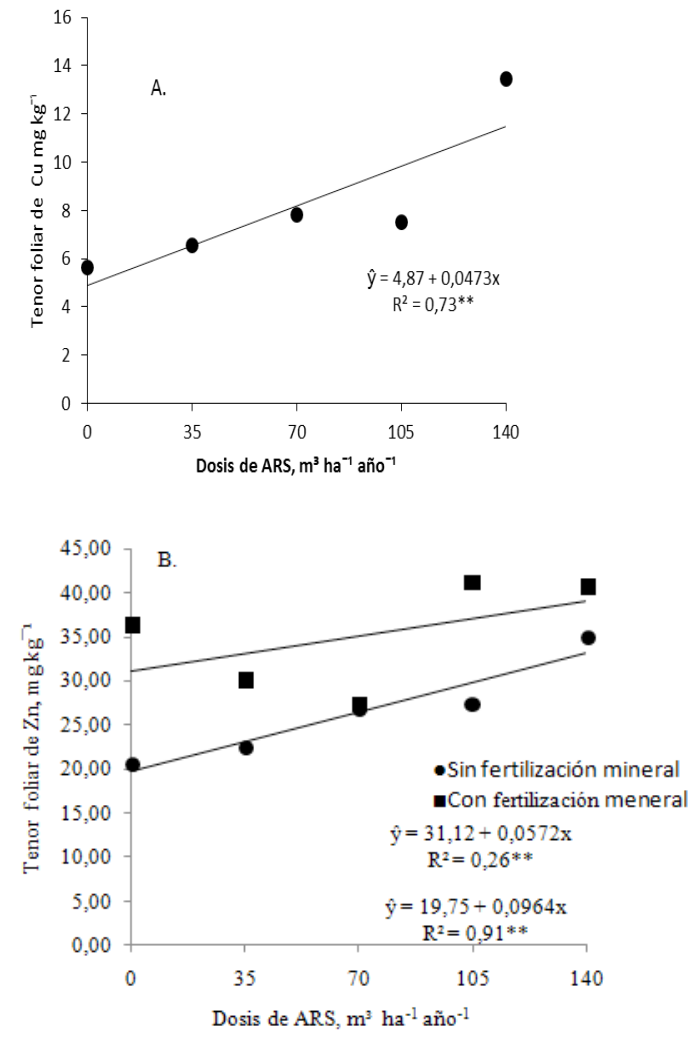

** significantivo $(\mathrm{p}<0,01),{ }^{*}$ significantivo $(\mathrm{p}<0,05)$.

Figura 5. Dosis de agua residual de suinocultura, para tenores foliares de $\mathrm{Cu}(\mathrm{A})$ y tenores foliares de $\mathrm{Zn}$ en maíz (B).

El zinc es el micronutriente más exigido por el maíz, sin embargo, en exceso puede perjudicar el aprovechamiento de otros nutrientes metálicos, como el $\mathrm{Cu}$, lo que puede predisponer a la planta a la incidencia de enfermedades (FANCELLI, 2010).

Trabajando con dosis de ARS de 0, 20, 40 y 80 $\mathrm{m}^{3} \mathrm{ha}^{-1}$, en Rhodic Paleudult en Santa Maria RS, GIROTTO et al. (2010), analizando la exportación de $\mathrm{Cu}$ y $\mathrm{Zn}$ en granos de maíz, encontró concentraciones mayores de $\mathrm{Zn}$ que de $\mathrm{Cu}$. El autor atribuye este comportamiento a la capacidad de la planta de maíz en la extracción de Zn.

\section{CONCLUSIONES}

- La aplicación de ARS proporciona aumento en los tenores de $\mathrm{P}$, en las camadas de $0-0,10$ e 0,10-0,20 m en SSD, posterior al cultivo de soja y maíz segunda zafra.

- Las dosis de 105 y $140 \mathrm{~m}^{3} \mathrm{ha}^{-1}$ año $^{-1}$ no deben ser aplicadas en la región oeste de Paraná, por representar riesgos de contaminación al medio ambiente, por incrementar niveles de $\mathrm{P}$ en Rhodic Kandiudox.

- El tenor de carbono orgánico no fue alterado significativamente en las camadas muestreadas.

- Los tenores foliares de $\mathrm{Cu}$ y $\mathrm{Zn}$ del cultivo de soja fueron adecuados, para el maíz hubo incremento en los tenores de $\mathrm{Cu}$ y $\mathrm{Zn}$ con aumento de las dosis de ARS.

- Los tenores de $\mathrm{Cu}$ y $\mathrm{Zn}$ en el suelo no presentaron niveles de contaminación $\mathrm{y}$ exceso, en función a las dosis de ARS.

- En base a los resultados, la dosis más adecuada para este suelo es la de $40 \mathrm{~m}^{-3} \mathrm{ha}^{-1} \mathrm{ano}^{-1}$.

- La fertilización mineral, no proporcionó aumento en los tenores de $\mathrm{K}$ en el suelo, sin embargo, aumentó la disponibilidad de P.

\section{REFERENCIAS BIBLIOGRÁFICAS}

ABIPECS - Associação Brasileira da Indústria Produtora e Exportadora de Carne Suína Estatísticas.Produção brasileira de carne suína - 2004 a 2012.Disponível em: <http://www. abipecs.org.br/uploads/relatorios mercado-interno/ produção_2012.pdf>. Acesso em: 24 fev. 2015.

AITA, C.; GIACOMINI, S.J.; HUBNER, A.P. Nitrificação do nitrogênio amoniacal de dejetos líquidos de suínos em solo sob sistema de plantio direto. Pesquisa Agropecuária Brasileira, Brasília,v.42, n.1 p.95-102, 2007.

AITA, C.; GIACOMINI, S.J. Nitrato no solo com a aplicação de dejetos líquidos de suínos no milho em plantio direto. Revista Brasileira de Ciência do Solo, Viçosa, v.32, p.2101-2111, 2008.

ASSMANN, T.S.; ASSMANN, J.M.; CASSOL, L.C.; DIEHL, R.C, MANTELIC, MAGIERO, E.C Desempenho da mistura forrageira de aveiapreta mais azevém e atributos químicos do solo em função da aplicação de esterco líquido de suínos. Revista Brasileira de Ciência do Solo,Viçosa,v.31, n.15, p.15-23, 2007. 
BARNETT, G.M. Phosphorus forms in animal manure. Bioresource Technology, Essex, Inglaterra, v.49, n.39, p.147, 2004.

BASSO, C.J.; CERETTA, C.A.; FLORES, E.M.M.; GIROTTO, E.Teores totais de metais pesados no solo após aplicação de dejeto líquido de suínos. Ciência Rural, Santa Maria, v.42, n.4, p.653-659, 2012.

BERTONCINI, E.I. Tratamento de efluentes e reuso da água no meio agrícola. Revista Tecnologia \& Inovação Agropecuária, Jaboticabal, v.1.n.1, p.152-169, 2008.

BERTHRONG, S.T.; BUCKLEY, D.H.; DRINKWATER, L.E. Agricultural management and labile carbon additions affect soil microbial community structure and Interact with carbon and nitrogen cycling. Microbial Ecology,New York, v.5, n.66, p.158-170, 2013.

BERWANGER, A.L, CERETTA, C.A.; RHEINHEMEIER, D. Alterações no teor de fósforo no solo com aplicação de dejetos líquidos de suínos. Revista Brasileira de Ciência do Solo,Viçosa, v.32, n.6, p.2525-2532, 2008.

BLESH, J.; DRINKWATER, L.E.The impact of nitrogen source and crop rotation on nitrogen mass balances in the Mississippi River Basin. Ecological Applications,Tempe, Arizona, v.23, p.1017-1035, 2013.

BORGHI, E.; MELLO, L.M.M.; CRUSCIOL, C.A.C. Adubação por área e por planta, densidade populacional edesenvolvimento do milho em função do sistema demanejo do solo. Acta Scientiarum Agronomy,Marigá, v.26, n.3, p.337345, 2004.

CANTERELLA, H.; MONTEZANO Z. F.Nitrogênio e enxofre. In.: PROCHONOW, L. I.; CASARIN, V.; STIPP, S.R (eds). Boas Práticas para o uso eficiente de fertilizantes. Piracicaba: INPI, 2010. v.2, p.7-35.

CASSOL, P.C.; COSTA, A.C.; CIPRANDI, O.;
PANDOLFO, C.M.;ERNANI,P.R. Disponibilidade de macronutrientes e rendimento de milho em Latossolo fertilizado com dejeto suíno.Revista Brasileira de Ciência do Solo, Viçosa,v.36, n.6, p.1911-1923, 2012.

CERETTA, C.A.; LORENSINI, F.; BRUNETTO, G.; GIROTTO, E.; GATIBONIL, C.; LOURENZI, C.R.; TIECHER, T.L.; DE CONTI, L.; TRENTIN, G.; MIOTTO, A. Frações de fósforo no solo após sucessivas aplicações de dejetos de suínos em plantio direto. Pesquisa Agropecuária Brasileira, Brasília, v.45,n.6, p.593-602,2010.

CONAMA - CONSELHO NACIONAL DO MEIO AMBIENTE.Resolução no 375/2006, de 29/8/2006. 2006. Disponível em: <http://www.mma.gov.br/ port/conama/legiabre.cfm?codlegi $=506>$. Acesso em: 03 jul. 2015.

CRUSCIOL, C.A.C.; MORO, E.; LIMA, EDO, V.; ANDREOTTI, M. Taxas de decomposição e de liberação de macronutrientes da palhada de aveia preta em plantio direto. Bragantia, Campinas, v.67, n.2, p.481-489, 2008.

EMBRAPA - Empresa Brasileira de Pesquisa Agropecuária. Centro Nacional de Pesquisa de Solos. Sistema brasileiro de classificação de solos. 3.ed. Brasília, 2013. 353p.

EMBRAPA - Empresa Brasileira de Pesquisa Agropecuária. Tecnologias de produção de soja Região Central do Brasil 2014. Londrina: Embrapa Soja, 2013. 265p. (Sistemas de Produção / Embrapa Soja, n.16). Disponível em: http: // www. infoteca. cnptia. embrapa. br/ bitstream/ doc/ 975595/1/ SP16online.pdf>. Acesso: 18 fev. 2016.

FACTOR, T.L.; ARAÚJO, J.A.C.; DE VILELLA JUNIOR, L.V.E. Produção de pimentão em substratos e fertirrigação com efluente de biodigestor. Revista Brasileira de Engenharia Agrícola e Ambiental, Campina Grande, v.12, n.2, p.143-149, 2008.

FANCELLI, A.L. MilhoIn: PROCHONOW, L.I.; CASARIN, V.; STIPP, S.R (eds). Boas Práticas 
para o uso eficiente de fertilizantes. Piracicaba: INPI, 2010.v.3, p.43-89.

FERREIRA, D.F. SISVAR: a computer statistical analysis system. Ciência e Agrotecnologia, Lavras, v.35, n.6, p.1039-1042, 2011.

FRIGO, E.P.; SAMPAIO, S.C.; FREITAS, P.S.L.; QUEIROZ, M.M.F.; NÓBREGA, L.H.P.; MALLMANN, L.S. Desempenho do sistema de gotejamento e de filtros utilizando água residuária da suinocultura. Irriga, Botucatu, v.11, n.3, p.305318, 2006.

GATIBONI, L.C.; BRUNETTO, G.; KAMINSKI, J., RHEINHEIMER, D.S.; CERETTA, C.A.; BASSO, C.J. Formas de fósforo no solo após sucessivas adições de dejeto líquido de suínos em pastagem natural. Revista Brasileira de Ciência do Solo, Viçosa, v.32, n.4, p.1753-1761, 2008.

GIROTTO, E.; CERETTA, C.A.; BRUNETTO, G.; SANTOS, D.R.; SILVA, L.S.; LOURENZI, C.R.; LORENSINI, F.; VIEIRA, R.C.B.; SCHMATZ, R. Acúmulo e formas de cobre e zinco no solo após aplicações sucessivas de dejeto líquido de suínos. Revista Brasileira de Ciência do Solo, Viçosa, v.34, p.955-965, 2010.

GUPTA, U.C. Micronutrientes e elementos tóxicos em plantas e animais. In: FERREIRA, M.E.; CRUZ, M.C. P.; RAIJ B.VAN.; ABREU, C.A. Micronutrientes e elementos tóxicos na agricultura. Jaboticabal: CNPq/FAPESP/POTAFOS, 2001. p.13-42.

HEDLEY, M.J.; STEWART, J.W.B.; CHAUHAN, B.S. Changes in inorganic and organic soil phosphorus fractions induced by cultivation practices and by laboratory incubations. Soil Science Society of America Journal, v.46, p.970976, 1982.

HERNANDEZ D, PLAZAC,SENESI N, POLO A . Detection of copper(II) and zinc(II) binding to humic acids from pig slurry and amended soils by fluorescence spectroscopy. Environmental Pollution, v.143, p.212-220, 2006.
KUNZA, HIGARASHI M.M.; OLIVEIRA P.A.O. Tecnologias de manejo e tratamento de dejetos de suínos estudadas no Brasil. Cadernos de Ciência\&Tecnologia, Rio de Janeiro, v.22, p.651665, 2005.

JONDREVILLEC, REVYPS, DOURMAD J.Y. Dietary means to better control the environmental impact of copper and zinc by pigs from weaning to slaughter. Livestock Production. Science, v.84, n.2, p.147-156, 2003.

LANA, M.C.; FEY, R.; FRADOLOSO, J.F.; RICHART, A.; FONTANIVA, S.Análise química de solo e tecido vegetal: práticas de laboratório. Marechal Cândido Rondon, 2010.

LOURENZIC, R.; CERETTA, C.A.; SILVALS, TRENTING, GIROTTO, E.; LOURENSINI, F.; TIECHERTL, BRUNETTO, G.Soil chemical properties related to acidity under successive pig slurry applications. Revista Brasileira de Ciência do Solo,Viçosa, v.35, p.1827-1836, 2011.

MARTINEZ, H.E.P.; CARVALHO, J.G.; SOUZA, R.B. Diagnose foliar (1999). In: RIBEIRO, A.C.; GUIMARÃES, P.T.G.; ALVAREZ, V.V.H. Recomendação para uso de corretivos e fertilizantes em Minas Gerais: $5^{\mathrm{a}}$ Aproximação. Viçosa: Comissão de fertilidade do solo do Estado de Minas Gerais, p.143-168.

MEDEIROS, S.D.; HANS, G.; SOARES, F.A.L . Cultivo de flores com o uso de água residuária e suplementação mineral. Engenharia Agrícola, Jaboticabal, v.30, n.6, p.1071-1080, 2010.

MORI, F.M.; FAVRETTO, N.; PAULETTI, V.; DIECKOW, J.; SANTOS, W.L. Perda de água, solo e fósforo com aplicação de dejeto líquido bovino em latossolos ob plantio direto e com chuva simulada. Revista Brasileira de Ciência do Solo, Viçosa, v.33, n.3, p.189-198, 2009.

PAULETTI, V.; MOTTA, A.C.V.; SERRAT, B.M.; FAVARETTO, B.M.; FAVARETTO, N.; ANJOS, A. Atributos químicos de um Latossolo Bruno sob sistema plantio direto em função da estratégia de 
adubação e do método de amostragem de solo. Revista Brasileira de Ciência do Solo, Viçosa, v.33, p.581-590, 2009.

PEREIRA, D. Decomposição e mineralização de adubos orgânicos acondicionados em cápsulas porosas. 2011. 115f. Dissertação (Mestrado em engenharia agricola) - Programa de Pós graduação em engenharia agrícola, Universidade Estadual do Oeste do Paraná.Cascavel.

Raij, B. van. Fertilidade do solo e manejo de nutrientes. International Plant Nutrition Institute. Piracicaba, 2011.

ROSOLEM C.A.; MATEUS, G.P.; GODOY, L.J.G.; FELTRAN, J.C.; BRANCALIÃO, S.R. Morfologia radicular e suprimento de potássio às raízes de milheto de acordo com a disponibilidade de água e potássio. Revista Brasileira de Ciência do Solo, VIÇOSA, v.27, p.875-884, 2003.

SCHERER, E.E.; AITA, C.; BALDISSERA, I.T. Avaliação da qualidade do esterco de suínos da região Oeste catarinense para fins de utilização como fertilizante. EPAGRI, Florianópolis, 1996.

SCHERER, E.E.; BALDISSERA, I.T.; NESE, C.N. Propriedades químicas de um Latossolo Vermelho sob plantio direto e adubação com esterco suínos. Revista Brasileira de Ciência do Solo, Viçosa, v.31, p.123-131, 2007.

SCHIPANSKI, M.E, BENNETT, E.M. The influence of agricultural trade and livestock production on the global phosphorus cycle. Ecosystems, v.15, n.2, p.256-268, 2012.

SHARPLEY, A.; DANIEL, T.C.; SIMS, J.T.; POTE, D.H. Determining environmental lysound soil phosphorus levels.JournalSoilWaterConservat ion,v.51, p.160-166, 1996.

SMANHOTTO, A.; SOUZA, A.P.; SAMPAIO, S.C.; NÓBREGA, L.H.P.; PRIOR, M. Cobre e zinco no material percolado e no solo com a aplicação de água residuária de suinocultura em solo cultivado com soja. Engenharia Agrícola, Jaboticabal, v.30, p.346-357, 2010.

SOCIEDADE BRASILEIRA DE CIÊNCIA DO SOLO. Comissão de Química e Fertilidade do SoloManual de adubação e calagem para os Estados do Rio Grande do Sul e de Santa Catarina. Porto Alegre: SBCS - Núcleo Regional Sul, 2004.107p.

USEPA - United States Environmental Protection. Agency 40 CFR-Standards for the use and disposal of sewage sludge. Washington. Part 503.p.93879415 (1993). (Federal Register, 58, 32).

e sludge. Washington. Part 503.p.9387-9415 (1993). (Federal Register, 58, 32). 